\title{
An overview of the opioid crisis
}

\section{Framing the opioid crisis in the context of the global drug problem}

\author{
Tiago Ribeiro, Sasha Ayoubzadeh
}

\begin{abstract}
The objective of this paper is to highlight the current state of the opioid crisis in Canada, framing it in the context of the global drug problem. The effects of the Opioid Crisis seen in London are part of a larger crisis occurring in North America. The USA has declared the opioid crisis a national emergency and we can expect a similar statement here in Canada as opioid related hospitalizations and deaths continue to rise. Although media attention continues to increase, we continue to see worsening statistics highlighting a flaw in how this complex issue is currently being addressed. Much like how attempts to prevent worsening of the opioid crisis have failed, globally, attempts to reduce the use and misuse of all illicit drugs have failed. Two key documents written by The Global Commission on Drug Policy will be reviewed to provide further insight while highlighting the need to challenge how we currently approach not just the opioid crisis but also the "war on drugs".
\end{abstract}

\section{INTRODUCTION}

An average of 4 overdose related deaths per day - an alarming statistic. ${ }^{1}$ This number, released by the British Columbia (BC) Coroners Service, indicates the number of overdose related deaths occurring daily in BC between January 1, 2017 and October 31, 2017. ${ }^{1}$ Accordingly, there has been a $70.4 \%$ increase in the number of illicit drug overdose-related deaths in BC from 2015 to 2016. ${ }^{1}$ This dramatic increase is indicative of the increasing trends seen nationally. In Ontario, as of 2015, the annual death rates have almost quadrupled since 1991, going from a total of 144 to 734 overdoserelated deaths annually. ${ }^{2}$ This reflects an average of 2 overdoserelated deaths occurring daily. When we assess the problem locally, it becomes clear that London has also been affected. The LondonMiddlesex county ranked 11th in Ontario for high-strength opioid use in 2015. ${ }^{3}$ Furthermore, London ranked 13th in Ontario for opioid-related deaths in 2013, and the opioid crisis has been on the rise since. ${ }^{3}$ This has all contributed to London officially declaring a public health emergency in 2016 due to HIV and hepatitis outbreaks, which has been associated with increased intravenous drug use (IVDU). ${ }^{4}$

Nationally, Canada finds itself in the midst of an opioid crisis, with an average of 16 hospitalizations daily related to opioid poisoning. ${ }^{5}$ Moreover, the rate of Emergency Department (ED) visits continues to rise, increasing by almost $50 \%$ in the past 5 years in Ontario. ${ }^{5}$ Although the opioid crisis has roots in overprescription by medical practitioners, illicit fentanyl and heroin use continues to increase and contribute to the high rates of overdose. ${ }^{6,7}$ According to a statement given by Dr. Theresa Tham, Canadian Chief Public Health Officer, fentanyl deaths "more than doubled in the first 3 months of 2017 compared to the same period in 2016". ${ }^{8}$ Not only does the opioid crisis come at a high social cost, but there is also significant financial burden from opioid-related costs to the Canadian healthcare system, costing approximately $\$ 15$ million in 2011. ${ }^{9}$ Furthermore, this calculated cost is a conservative estimate as it does not account for those arriving to the ED but not being admitted, those receiving treatment in the community and outpatient services, and those admitted for injuries or accidents related to opioid use. ${ }^{9}$

Internationally, the opioid crisis occurring in Canada is not unique. The United States, Europe, China, Saudi Arabia, Lebanon, and Australia all have alarming rates of opioid abuse. ${ }^{10}$ Reports show a worldwide increase in opioid abuse, especially in middleand high-income countries. ${ }^{11}$ Although some data is available, the United Nations continues to work with many countries to improve data collection on opioid abuse as this remains a barrier to fully understanding the extent of this issue. ${ }^{10}$ What is clear at this time is that the "war on drugs" has proven ineffective in decreasing substance abuse rates. The United States have declared their opioid crisis a national emergency, and the Canadian government is under pressure to do the same. Given the increasing burden of the opioid crisis both on healthcare systems and societies, it has become clear that there is need to change how this issue is addressed.

Considering the current state of the opioid crisis and drug problem locally and internationally, it was felt to be both important and informative to share the main findings and recommendations from 2 key documents released by The Global Commission on Drug Policy (GCDP). The GCDP is an international group composed of political figures, intellectuals, and business leaders who work together to "bring to the international level an informed, sciencebased discussion about humane and effective ways to reduce the harm caused by drugs to people and societies". By looking globally, this organization highlights important lessons from around the world that can be useful as we move forward and think of new strategies to address both the opioid crisis and illicit drug use. Two recent reports will be summarized within this article: The GCDP's 2016 report, "Advancing Drug Policy Reform," ${ }^{2}$ and their recent position paper titled "The Opioid Crisis in North America". ${ }^{13}$

\section{"THE OPIOID CRISIS IN NORTH AMERICA"}

The 2017 position paper was written following recognition of the opioid crisis in both Canada and the United States. ${ }^{13}$ Through its position paper, the GCDP highlights the complexity of the crisis and refers to the many contributing factors, including: increase in 
prescription opioids, increase in non-medical opioid use, inadequate treatment services, and an increase in the use of synthetic opioids. Through their analysis, the report considers the history of health policy and economics and how that has led to the position we are in today. The GCDP's main recommendations include working towards finding the appropriate balance in regulation to provide proper pain care while minimizing the possibility of misuse of these medications and making a concerted effort towards proven harm reduction and treatment measures currently available. These recommendations are meant to minimize the negative outcomes of the current crisis. However, the GCDP continues to advocate for decriminalization of personal use and possession of illicit drugs as a strong step towards a definitive solution. Below are some of the important points made in the position paper:

- The healthcare systems in Canada and the United States are not set up to effectively care for those with addiction; treatment is still dominated by abstinence-focused programs even though substitution therapy has continually proven to reduce mortality.

- The prejudice many still hold against substitution therapy negatively affects the opioid crisis, leading to overregulation and decreased access to methadone treatment.

- Given the demographics of those most affected by chronic pain and those who most often overdose, the epidemic seems to be driven by illegal rather than medical use of opioids

- Though guidelines to reduce opioid prescriptions have led to a decrease in medical supply, incidence of overdose is still going up. This highlights that without providing adequate treatment and harm reduction measures, we fail those our healthcare system aims to serve. Individuals are left to seek out illicit sources with unknown purity and potency, increasing their risk of overdose.

\section{"GLOBAL COMMISSION ON DRUG POLICY 2016 REPORT - ADVANCING DRUG POLICY REFORM"}

The GCDP's 2016 report describes full decriminalization and removal of all punitive responses of drug possession and use as an essential step in drug policy reform towards regulation. ${ }^{12}$ The report offers strong support in the form of relevant research and lessons from different systems around the globe with a focus on serving those impacted most, drug users. Below are some of the report's supporting points:

- Prohibition has failed - such policies have led to social and health consequences for all of society. Today, violations of human rights and unjust law enforcement continue to occur which does not serve society's effectively.

- Regulating the drug market gives governments the power to bring positive economic, health, and societal changes while taking the power away from illegal markets.

- Penalizing possession of drugs for personal use - when no risk is present to others - is an unjustified violation of an individual's right to privacy and thus in conflict with the principles of personal autonomy and human dignity.
- Criminalization has fueled the global pandemic of HIV and hepatitis $\mathrm{C}$ as criminalization pushes people away from beneficial services such as needle and syringe programs and towards risky behaviors to avoid law enforcement.

- Well-implemented decriminalization programs globally are promising examples. Decriminalization in conjunction with a substantial effort towards harm reduction and treatment services has been effective.

\section{CONCLUSION}

Criminalization of drug use has not been effective at addressing the root cause of substance abuse nor has it achieved the goal of reducing or eliminating drug use. Evidenced by an increased incidence of drug use, hepatitis C and HIV outbreaks, and overpopulated prisons, an overhaul in drug policy is necessary. Much like the global drug problem, the opioid crisis is one that we as a society continue to fail to address properly. Overdose numbers continue to rise at an alarming rate, without an appropriate increase in proven reduction measures. The stigma and cultural viewpoints that bias our societal views on drug use may be clouding our ability to decide on effective action that will address these problems. Through research at an international level and consolidation of global lessons, the GCDP's reports serve to spark new ways of thinking about addressing these challenges in hopes of leading to true productive change for the betterment of societies globally. It is time to challenge our current failed approaches to dealing with drug crises to make room for novel, effective methods that better serve those in need.

\section{REFERENCES}

1. Illicit Drug Overdose Deaths in BC; January 1, 2007 - October 31, 2017 [Internet]. Burnaby ( BC): BC Coroners Service; 2017 Dec 11 [cited 2017 Dec 15]. Available from: https://www2.gov.bc.ca/assets/gov/ public-safety-and-emergency-services/death-investigation/statistical/ illicit-drug.pdf.

2. Gomes T, Greaves S, Martins D, et al. Latest Trends in Opioid Related Deaths in Ontario: 1991 to 2015. Toronto (ON): Ontario Drug Policy Research Network [Internet]. 2017 Apr [cited 2017 Oct 15]. Available from: http://odprn.ca/wp-content/uploads/2017/04/ODPRN-Report Latest-trends-in-opioid-related-deaths.pdf.

3. Martins D, Greaves S, Tadrous M, et al. Opioid Use and Related Adverse Events in Ontario. Toronto (ON): Ontario Drug Policy Research Network [Internet]. 2016 Nov [cited 2017 Oct 15]. Available from: http://odprn.ca/wp-content/uploads/2016/11/ODPRN-OpioidUse-and-Related-Adverse-Events-Nov-2016.pdf.

4. Persons who inject drugs in Middlesex-London: An update [Internet]. London (ON): Middlesex-London Health Unit; 2016 Jun 16 [cited 2017 Oct 15]. Available from: https://www.healthunit.com/uploads/201606-16-report-040-16.pdf

5. Opioid-Related Harms in Canada [Internet]. Ottawa (ON): Canadian Institute for Health Information; 2017 [cited 2017 Oct 20]. Available from: https://www.cihi.ca/sites/default/files/document/opioidharms-chart-book-en.pdf

6. Kolodny A, Courtwright DT, Hwang CS, et al. The Prescription Opioid and Heroin Crisis: A Public Health Approach to an Epidemic of 
Addiction. Annu Rev Public Health. 2015 Mar;36:559-574

7. Haddox JD, Joranson D, Angarola RT, et al. The use of opioids for the treatment of chronic pain: a consensus statement from the American Academy of Pain Medicine and the American Pain Society. Clin J Pain. 1997 Mar;13:6-8.

8. Rising hospitalizations due to opioid crisis puts a burden on Canada's health system: report [Internet]. Toronto (ON): The Canadian Press; 2017 Sept 14 [cited 2017 Oct 15]. Available from: https://www.thestar. com/news/canada/2017/09/14/rising-hospitalizations-due-to-opioidcrisis-puts-a-burden-on-canadas-health-system-report.html.

9. Young MM, Jesseman RA. The impact of substance use disorders on hospital use [Internet]. Ottawa (ON): Canadian Centre on Substance Abuse; 2014 Nov [cited 2017 Oct 15]. Available from: http://www.ccsa. ca/Resource\%20Library/CCSA-Substance-Use-Hospital-ImpactReport-2014-en.pdf

10. Martins SS, Ghandour L. Nonmedical use of prescription drugs in adolescents and young adults: not just a Western phenomenon. World Psychiatry. 2017 Feb;16(1):102-104.

11. Martins SS, Sampson L, Cerdá M, et al. Worldwide prevalence and trends in unintentional drug overdoses: a systematic review of the literature. Am J Public Health. 2015 Nov;105(11):29-39.

12. Advancing Drug Policy Reform: A new approach to decriminalization [Internet]. Global Commission on Drug Policy; 2016 [cited 2017 Oct 20]. Available from: http://www.globalcommissionondrugs.org/wpcontent/uploads/2016/11/GCDP-Report-2016-ENGLISH.pdf.

13. Position Paper: The Opioid Crisis in North America [Internet]. Global Commission on Drug Policy; 2017 Oct [cited 2017 Oct 20]. Available from: http://www.globalcommissionondrugs.org/wp-content/ uploads/2017/09/2017-GCDP-Position-Paper-Opioid-Crisis-ENG.pdf

\section{Bluewater Health Sarnia \& Petrolia, Ontario}

Bluewater Health is recruiting for the following positions to provide services to the residents of Sarnia-Lambton both in the community and at the hospital.

- Paediatrician

- Hospitalists

- Internists with Endocrinology or Rheumatology interest
- Neurologist

- Psychiatrist

- Emergency Physicians

- Rheumatologist
- Orthopaedic Surgeon

- Dermatologist

- Infectious Disease (Part Time)

Bluewater Health operates 326 beds at hospitals in Petrolia and Sarnia. We are award winning, Accredited with Exemplary Standing, and have state-of-the-art facilities. We offer an array of specialized acute, complex continuing care, allied health and ambulatory care services including:

- A broad range of diagnostic services, including CT, and MRI.

- Full spectrum of specialists available 24/7 (Neurosurgery and Interventional Cardiology not available) - Closed Critical Care Unit • District Stroke Centre • Schedule 1 Psychiatric Unit - Affiliation with Western University's Schulich Medicine Distributed Education.

We are committed to improving the patient experience using engagement, lean, and innovation.

Situated on the shores of Lake Huron at the border to Michigan,

Sarnia offers excellent quality of life, sports, arts and culture, education, state of the art health care, and beautiful natural environment.

To inquire about these positions, please contact:

Dr. Mike Haddad, Interim Chief of Professional Staff Bluewater Health

Email: Medical_affairs@bluewaterhealth.ca Tel: 519-464-4400 ext 4534.

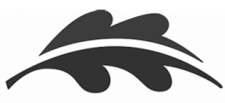

B LUE WAT ER

H E A L T H

Life, health and renewal. 